\title{
VIVER COM MAIS DE 60 ANOS: A PROPÓSITO DA POLÍTICA SOCIAL PARA AS PESSOAS IDOSAS
}

Ademir Alves da Silva ${ }^{1}$

\section{RESUMO}

No contexto das iniciativas de denúncia e de combate à "cultura anti-idoso", marcada pelo preconceito e a segregação, este texto consiste em uma abordagem crítica dos principais aspectos da Política Social Brasileira para as Pessoas Idosas, destacando os marcos legais e as manifestações da sociedade civil, especialmente nas duas últimas décadas, em defesa dos direitos sociais dos idosos, a partir do Estatuto do Idoso. Os quadros-sinóticos utilizados devem-se à natureza didática do texto, elaborado sob o propósito de subsidiar decisões técnico-operativas na área em questão.

PALAVRAS-CHAVE: Pessoas Idosas, Velhice, Envelhecimento, Política Social, Legislação Social

Velho, idoso, ancião, geronte, gerontino, provecto - com sutis distinções entre elas - são expressões utilizadas para designar a condição da pessoa que envelheceu.

É curiosa a dança terminológica em torno das tentativas de encontrar a melhor denominação para tal fase da vida: terceira idade, maior idade, maturidade e melhor idade. Convencionou-se, afinal, que a melhor designação para a pessoa que se encontre em tal fase da vida é idoso, sendo chamado de envelhecimento o conjunto de fenômenos que marcam tal período.

\footnotetext{
${ }^{1}$ Professor de Política Social nos cursos de Serviço Social e de Relações Internacionais e Coordenador do NEPPS - Núcleo de Estudos e Pesquisas sobre Políticas Sociais no Programa de Pós-Graduação em Serviço Social da PUC-SP. É integrante do Conselho Editorial da área de Serviço Social da Editora Cortez, pela qual publicou o livro A gestão da Seguridade Social brasileira: entre a política pública e o mercado, $3^{\mathrm{a}}$ edição, 2010. Atuou por 25 anos na Prefeitura de São Paulo, acumulando experiência na gestão de políticas públicas, particularmente na área de Assistência Social. Foi membro do Conselho Municipal dos Direitos da Criança e do Adolescente, do Conselho Municipal de Assistência Social e do Conselho do Orçamento Participativo em São Paulo. E-mail: adecris@,uol.com.br.
} 
Idoso (a) e velhice em português, persona mayor e vejez em espanhol, persona anziana e vecchiaia em italiano, elderly e old age em inglês, âgé $e$ agée e vieillesse em francês denominam o período da vida posterior aos 60 anos.

Mas, o número de anos não é o mais relevante. Para além dos fenômenos naturais - inerentes ao processo de envelhecimento - que costumam marcar, de modos diferentes, essa fase da vida, a velhice é um constructo, uma categoria socialmente construída.

Há diferentes modos de envelhecer e de ser idoso. A despeito de certas características atribuídas ao idoso em geral, não há um idoso universal. As inserções territoriais, etárias, raciais, étnicas, de gênero e de classe social constituem referências identitárias que precedem, transcendem e sobredeterminam a condição biológica do idoso. Então, saúde e doença, higidez e debilidade dependem de um conjunto de fatores que marcam a vida social e o contexto cultural. Há um "idoso em geral" que esconde e, ao mesmo tempo, revela um "idoso em particular" em seu tempo e espaço sociocultural.

Na sociedade contemporânea, em que prevalecem os capitais e a lógica do mercado, sob a égide de valores como competitividade, status social decorrente do patrimônio e diferenciação pelos hábitos de consumo, o velho é concebido, de modo geral, em oposição ao jovem.

Há uma cultura anti-idoso que privilegia a juventude e tudo que se associa a ela: vigor, tônus muscular e performance sexual, segundo os padrões estéticos dominantes. Prevalece um tipo de pensamento que desqualifica e descredencia o idoso para o convívio social com aqueles que são fisicamente mais ágeis e que se presumem mentalmente mais espertos.

E o idoso tende a ser visto pela perda da capacidade laborativa, pela improdutividade e pela incapacidade, passando a ser socialmente descartável, a despeito Revista Serviço Social \& Saúde. UNICAMP Campinas, v. X, n. 11, Jul. 2011 
das reservas intelectuais, afetivas, espirituais e estéticas acumuladas pela experiência vivida cuja densidade não corresponde às limitações de um corpo mais ou menos fragilizado e vulnerável, dependendo das condições da vida pregressa.

As inúmeras manifestações de preconceito e discriminação comparecem em frases do tipo: "Não tem o que fazer. E cabeça desocupada é oficina do diabo"; "Vá jogar milho pros pombos!”; “Já está com o pé na cova”; "Está mais pra lá do que pra cá"; "Já virou a curva da esperança"; "É um velho gagá". "Velho rabugento e ranzinza". Já se usou muito a expressão "velha coroca".

Então, os idosos tendem a ser segregados e confinados aos espaços privados da família - destacando-se a discriminação dentro da própria família - e das instituições de longa permanência. Não obstante, a família desempenha papel fundamental, sendo de sua responsabilidade, em primeiro lugar - conforme estabelecido pela legislação social brasileira - a proteção ao idoso, respondendo pela preservação de vínculos, pelo convívio e pelas trocas intergeracionais.

Famílias de idosos:

o idoso é chefe ou cônjuge.

Famílias com idosos:

o idoso é parente do chefe ou cônjuge.
Trocas intergeracionais:

- Apoio intergeracional descendente (dos mais velhos para os mais jovens)

- Apoio intergeracional ascendente (dos mais jovens para os mais velhos) (SAAD, 2004, p. 169ss)

Vem ocorrendo uma "revolução" pela idade. As pessoas estão permanecendo jovens por mais tempo e os velhos estão mais longevos e, enquanto segmento populacional crescente vem ganhando importância nos vários setores da vida social: na 
família, no mercado de trabalho, no mundo do consumo, no lazer e na cultura, na Internet, na legislação social e nas políticas públicas.

O fato é que os idosos representam importante parcela de consumidores e eleitores, chamando a atenção de bancos, empresas do ramo de serviços e políticos. Veja-se o assédio dos bancos aos aposentados com a sedutora oferta de empréstimos, avalizados pela regularidade da renda e pela garantia de pagamento pelo desconto na fonte pagadora. De outro lado, os guias de serviços para a "terceira idade" ou, pelo menos, para a parcela de maior renda entre os idosos. $\mathrm{E}$ as iniciativas dos políticos ao proporem projetos de lei em favor dos idosos e ao criarem oportunidades para a aglutinação de idosos com fins político-eleitorais.

E a velhice é feminina. De fato, é crescente o protagonismo da mulher idosa, trabalhadora, chefe de família, cuidadora, aposentada, pensionista ou beneficiária do BPC, típica usuária da Assistência Social, cidadã. Vale lembrar, a propósito, a frase de Odete, aos 75 anos, participando de uma Conferência Municipal de Assistência Social: "Serei protagonista sempre, antagonista às vezes, excluída nunca". É necessário, no entanto, contrapor a frase de outra idosa que, a partir de uma outra trajetória de vida, queixa-se: - Meu maior desgosto é não ser dona de mim.

Reafirmando a expressão majoritária da mulher no crescente segmento de idosos ou sua condição de cuidadora de pessoa idosa, os eventos e a literatura da área apontam a necessidade de adoção da perspectiva das relações de gênero na formulação das políticas sociais para idosos e o empowerment das mulheres para o envelhecimento com qualidade de vida. Os estudos (GOLDANI, 2004, p. 236) destacam ainda que de "recurso invisível", o trabalho da mulher na condição de cuidadora vem se tornando "recurso escasso", em função de sua inserção nos mais diversos setores da vida social, 
especialmente o mercado de trabalho, restando menor tempo para as tarefas domésticas que, tradicionalmente, abrangem os cuidados para com outros membros da família.

O reconhecimento da condição de idoso pode significar a convivência com aspectos limitantes (ver boxe abaixo) do envelhecimento, mas significa também valorizar suas conquistas, sob a perspectiva do envelhecimento com dignidade e qualidade de vida. Outra coisa é a visão social estereotipada da condição social do idoso, à maneira de um estigma ou de um fardo que se está condenado a carregar. É o caso em que a morte social tem efeito devastador sobre a condição biológica, precedendo a morte natural. A velhice torna uma pessoa mais vulnerável a certas patologias, mas a velhice não é em si mesma uma doença. Envelhecer não é, necessariamente, adoecer.

\section{Limitações para as:}

AFVD - Atividades funcionais da vida diária: andar dentro de casa, tomar banho, vestirse, comer e utilizar o banheiro.

AIVD - Atividades instrumentais da vida diária: preparar comida, cuidar do próprio dinheiro, fazer compras, tomar remédios e fazer serviços domésticos leves.

(SAAD, 2004, p. 194)

As várias fases da vida não podem ser vistas como justaposição de experiências datadas, mas representam um continuum, um todo articulado. É a vida de um sujeito - outrora uma criança, depois adulto e, mais tarde, idoso - em permanente busca da síntese de si mesmo como protagonista da história de sua geração e de toda a humanidade. Trata-se do processo de construção da identidade pela intersecção das várias fases vitais em um sujeito que é único e, ao mesmo tempo, representativo da experiência histórica de toda uma geração. 
No Brasil, são notáveis os avanços da legislação relativa à proteção social dos idosos, com base na identificação e no reconhecimento da célere mudança do perfil demográfico pelo crescente segmento populacional de idosos, a par da queda das taxas de natalidade e de mortalidade.

\section{CRONOLOGIA}

1982 - Primeira Assembleia Mundial sobre o Envelhecimento - Viena / ONU

1988 - Promulgação da Constituição Federal Brasileira

1993 - LOAS - Lei Orgânica da Assistência Social

1994 - Política Nacional do Idoso

1999 - Ano Internacional das Pessoas Idosas - Uma sociedade para todas as idades - ONU.

2002 - Segunda Assembleia Mundial sobre o Envelhecimento - Madri / ONU

2002 - Declaração de Toronto - Plano Internacional de Prevenção da Violência contra a Pessoa Idosa

2003 - Estatuto do Idoso

2003 - Campanha da Fraternidade - A fraternidade e os idosos: Vida, dignidade e esperança.

\section{O IDOSO NO CALENDÁRIO}

15 de Junho - Dia Mundial de Conscientização sobre a violência contra a Pessoa Idosa 01 de Outubro - Dia Mundial do Idoso

$1^{\circ}$ Sábado de Abril - Dia Municipal de Vacinação do Idoso em São Paulo

É na década de 1990 que ganham visibilidade as preocupações com a "terceira idade", mas os primeiros anos deste terceiro milênio é que abrigam uma profusão de iniciativas - dos governos ou da sociedade civil - conducentes à sensibilização e conscientização quanto aos fenômenos relacionados à velhice e à importância dos idosos e de suas demandas sociais, políticas, econômicas e culturais. Revista Serviço Social \& Saúde. UNICAMP Campinas, v. X, n. 11, Jul. 2011 


\section{Constituição Federal (1988)}

“Artigo 203. A assistência social será prestada a quem dela necessitar, independentemente da contribuição à seguridade social, e tem por objetivos:

I - a proteção à família, à maternidade, à infância, à adolescência e à velhice;

II - o amparo às crianças e adolescentes carentes;

III - a promoção da integração ao mercado de trabalho;

IV - a habilitação e reabilitação das pessoas portadoras de deficiência e a promoção de sua integração à vida comunitária;

$\mathrm{V}$ - a garantia de um salário mínimo de benefício mensal à pessoa portadora de deficiência e ao idoso que comprovem não possuir meios de prover a própria manutenção ou de te-la provida por sua família, conforme dispuser a lei"

"Artigo 231. A família, a sociedade e o Estado têm o dever de amparar as pessoas idosas, assegurando sua participação na comunidade, defendendo sua dignidade e bem-estar e garantindo-lhes o direito à vida.

Parágrafo $1^{\circ}$ - Os programas de amparo aos idosos serão executados preferencialmente em seus lares.

Parágrafo $2^{\circ}$ - Aos maiores de sessenta e cinco anos é garantida a gratuidade dos transportes coletivos urbanos"

\section{Constituição Estadual (1989)}

"Artigo 277. Cabe ao Poder Público, bem como à família, assegurar à criança, ao adolescente, ao idoso e aos portadores de deficiências, com absoluta prioridade, o direito à vida, à saúde, à alimentação, à educação, ao lazer, à profissionalização, à cultura, à dignidade, ao respeito, à liberdade e à convivência familiar e comunitária, além de coloca-los a salvo de toda forma de negligência, discriminação, exploração, violência, crueldade e agressão.

Parágrafo único: (...)

Artigo 278. O poder público promoverá programas especiais, admitindo a participação de entidades não governamentais e tendo como propósito:

III - garantia às pessoas idosas de condições de vida apropriadas, frequência e participação em todos os equipamentos, serviços e programas culturais, educacionais, esportivos, recreativos e de lazer, defendendo sua dignidade e visando à sua integração à sociedade.

VI - instalação e manutenção de núcleos de atendimento especial e casas destinadas ao acolhimento provisório de crianças, adolescentes, idosos, portadores de deficiências e vítimas de violência, incluindo a criação de serviços jurídicos de apoio às vítimas, integrados a atendimento psicológico e social

IX - criação e manutenção de serviços e programas de prevenção e orientação contra entorpecentes, álcool e drogas afins, bem como de encaminhamento de denúncias e atendimento especializado, referentes à criança, ao adolescente, ao adulto e ao idoso dependentes.

Artigo 280. É assegurado, na forma da lei, aos portadores de deficiências e aos idosos, acesso adequado aos logradouros e edifícios de uso público, bem como aos veículos de transporte coletivo urbano."

\section{Lei Orgânica do Município de São Paulo (1990)}

“Art. 225. O Município procurará assegurar a integração dos idosos na comunidade, defendendo sua dignidade e seu bem-estar, na forma da lei, especialmente quanto:

I - ao acesso a todos os equipamentos, serviços e programas culturais, educacionais, esportivos, recreativos, bem como a reserva de áreas em conjuntos habitacionais destinados à convivência e lazer;

II - a assistência médica geral e geriátrica;

III - a gratuidade do transporte coletivo urbano, para os maiores de 65 (sessenta e cinco) anos, e aposentados de baixa renda, vedada a criação de qualquer tipo de dificuldade ou embaraço ao beneficiário;

IV - a criação de núcleos de convivência para idosos;

$\mathrm{V}$ - o atendimento e orientação jurídica, no que se refere a seus direitos.

Art. 226 - O Município buscará garantir a pessoa portadora de deficiência sua inserção na vida social e econômica, através de programas que visem o desenvolvimento de suas potencialidades, em especial: I - a assistência, desde o nascimento, através da estimulação precoce, da educação gratuita e especializada, inclusive profissionalizante, sem limite de idade;

II - o acesso a equipamentos, serviços e programas culturais, educacionais, esportivos e recreativos;

III - a assistência médica especializada, bem como o direito à prevenção, habilitação e reabilitação, através de métodos e equipamentos necessários;

IV - a formação de recursos humanos especializados no tratamento e assistência dos portadores de deficiência; $\mathrm{V}$ - o direito à informação e à comunicação, considerando-se as adaptações necessárias.

Art. 227. O Município deverá garantir aos idosos e pessoas portadoras de deficiências o acesso a logradouros e a edifícios públicos e particulares de frequência aberta ao público, com a eliminação de barreiras arquitetônicas, garantindo-lhes a livre circulação, bem como a adoção de medidas semelhantes, quando da aprovação de novas plantas de construção, e a adaptação ou eliminação dessas barreiras em veículos coletivos". 
O marco polarizador desse movimento foi, no Brasil, a concepção de seguridade social consubstanciada na Constituição Federal de 1988, demarcando o teor da legislação social promulgada na sequência, sendo suas melhores expressões a LOAS - Lei Orgânica da Assistência Social (1993), a Política Nacional do Idoso (1994) e o Estatuto do Idoso (2003). O quadro à página (07) apresenta uma sinopse da legislação básica

Segundo o Estatuto do Idoso, Lei 10.741 de 01/10/03, idoso é a pessoa com mais de 60 anos. Em função de sua peculiar condição de idade, tem direito ao atendimento preferencial e prioritário na rede de serviços públicos e privados, com absoluta prioridade. Constitui obrigação da família, da comunidade, da sociedade e do Estado assegurar aos idosos, oportunidades e facilidades para preservação de sua saúde física e mental e seu aperfeiçoamento moral, intelectual, espiritual e social, em condições de liberdade e dignidade. A proteção social integral ao idoso compreende o direito à vida, saúde, alimentação, educação, cultura, esporte, lazer, trabalho, cidadania, liberdade, dignidade, respeito e convivência familiar e comunitária.

O direito à saúde abrange: atenção integral à saúde; acesso universal e igualitário ao SUS; cadastramento, atendimento geriátrico e gerontológico, unidades geriátricas de referência, atendimento domiciliar, reabilitação, gratuidade em medicamentos de uso continuado, próteses e órteses; direito de opção pelo tratamento de saúde mais favorável; direito a acompanhante quando internado; e, quando sem condições de opção, ajuda de curador, familiares ou médico.

Quanto ao direito ao trabalho destacam-se: direito ao exercício de atividade profissional; não discriminação e não fixação de limite máximo de idade; idade como critério de desempate em concurso público; profissionalização especializada; preparação dos trabalhadores para a aposentadoria; admissão de idosos por empresas privadas. 
O direito à seguridade social abrange: preservação do valor real dos salários no cálculo dos benefícios da Previdência Social; data-base é $1^{\circ}$ de maio; BPC a partir de 65 anos; benefício já concedido a outro membro da família não será computado para fins de cálculo da RFPC referida na LOAS; necessidade de projeto de lei de revisão dos critérios de concessão do BPC.

No âmbito da educação, cultura e lazer, destacam-se: preservação da memória e da identidade culturais; acesso preferencial e descontos de pelo menos $50 \%$ em eventos artísticos, culturais, esportivos e de lazer; espaços e horários especiais em meios de comunicação; conteúdos referentes ao processo de envelhecimento nos currículos mínimos dos diversos níveis de ensino formal; universidade aberta para idosos.

O direito à moradia digna abrange: prioridade na aquisição de imóvel para moradia própria; reserva de cota de $3 \%$ das unidades de projetos habitacionais; assistência integral na modalidade de entidade de longa permanência.

O direito ao transporte compreende: prioridade no embarque no sistema de transporte; gratuidade dos transportes coletivos públicos urbanos e semi-urbanos para os maiores de 65 anos; reserva de $10 \%$ dos assentos no transporte coletivo; reserva de 5\% das vagas nos estacionamentos públicos e privados; reserva de 2 vagas, para os idosos com renda até $2 \mathrm{SM}$, nos ônibus do sistema de transporte coletivo interestadual e desconto de $50 \%$ para os idosos que excederem às vagas.

No âmbito de justiça, o Estatuto estabelece: acesso à Justiça com prioridade na tramitação de processos e procedimentos e na execução de atos e diligências judiciais; proteção judicial dos interesses difusos, coletivos e individuais indisponíveis ou homogêneos (art. 78 ss); penalidades maiores para crimes contra idosos; nos casos de maus-tratos, comunicação à polícia, Ministério Público, conselhos municipal, estadual e 
nacional; medidas de proteção aplicáveis nos casos de ameaça ou violação de direitos por ação, omissão, falta ou abuso da família, curador, entidade, sociedade, Estado ou em razão de sua condição social. O Estatuto estabelece ainda as competências do Ministério Público (art. 72 ss).

O Estatuto contempla as políticas sociais básicas; a assistência social supletiva; os serviços especiais de prevenção e atendimento às vítimas de negligência, maus-tratos, exploração, abuso, crueldade e opressão; o serviço de identificação e localização de parentes ou responsáveis; a proteção jurídico-social.

Quanto às entidades assistenciais são estabelecidas as responsabilidades civil e criminal dos dirigentes das instituições quanto aos cuidados com idosos; as obrigações das entidades (art. 50); os princípios que devem reger os programas de institucionalização de longa permanência (art. 49); a fiscalização das entidades; as penalidades (art. 55); a apuração de irregularidades; e o treinamento e capacitação de cuidadores profissionais e familiares e grupos de autoajuda.

Segue-se uma sinopse da Política do Idoso nos âmbitos federal, estadual e municipal: 


\section{Política Nacional do Idoso - Lei 8.842 de 04/01/94}

\section{Objetivo:}

- Assegurar direitos do idoso, criando condições para a sua autonomia, integração Princípios: e participação efetiva na sociedade

- Participação na comunidade, defendendo dignidade, bem-estar e direito à vida

- Processo de envelhecimento e sociedade: objeto de conhecimento e informação para todos

- Não discriminação de qualquer natureza

- Idoso como o principal agente e destinatário das transformações efetivadas pela política do idoso

- Consideração das diferenças econômicas, sociais, regionais e contradições entre Diretrizes: o meio rural e urbano

- Formas alternativas de participação, ocupação e convívio

- Participação

- Priorização do atendimento através das próprias famílias

- Descentralização político-administrativa

- Capacitação e reciclagem dos recursos humanos

- Sistema de informações

- Divulgação de informações

- Priorização do atendimento ao idoso em órgãos públicos e privados

- Estudos e pesquisas sobre envelhecimento

- Vedada a permanência de portadores de doenças que necessitem de assistência médica ou de enfermagem permanente em instituições asilares de caráter social.

\section{Política Estadual do Idoso - Lei n. 9892 de 10/12/97}

\section{Finalidade:}

- Garantir ao cidadão com mais de sessenta anos as condições necessárias para continuar no pleno exercício da cidadania.

Princípios: igualdade e universalidade

- Direito à vida

- Direito à dignidade

- Direito ao bem estar

- Direito à participação na sociedade

Objetivos e metas:

- Resgatar a identidade, o espaço e a ação do idoso na sociedade;

- Integrar o idoso à sociedade em geral, através de formas alternativas de participação, ocupação e convívio;

- Estimular a organização dos idosos para participarem efetivamente da 
elaboração de sua política em nível nacional, estadual e municipal.

- Estimular a permanência dos idosos junto à família, em detrimento do atendimento asilar, à exceção dos idosos que não possuam família para garantir sua própria sobrevivência;

- Estimular a criação de Políticas Municipais por meio dos Conselhos Municipais dos Idosos;

- Capacitar os recursos humanos em todas as áreas ligadas ao idoso;

- Divulgar informações acerca do processo de envelhecimento como fenômeno natural da vida;

- Estabelecer formas de diálogo eficiente entre o idoso, a sociedade e os poderes públicos;

- Priorizar o atendimento ao idoso desabrigado e sem família;

- Apoiar e desenvolver estudos e pesquisas sobre questões relativas ao envelhecimento;

- Atender com dignidade o idoso de acordo com suas necessidades

\section{Política Municipal do Idoso - Lei n. 13.834/2004}

\section{Objetivo:}

- Gerar condições para a proteção e a promoção da autonomia, da integração e da participação efetiva do idoso na sociedade.

\section{Princípios:}

- Cooperação da sociedade, da família e do Município na promoção da autonomia, integração e participação do idoso na sociedade;

- Direito à vida, à cidadania, à dignidade, ao bem estar social;

- Proteção contra discriminação de qualquer natureza;

- Prevenção e educação para um envelhecimento saudável

- Universalização dos direitos sociais, a fim de tornar o idoso atendido pelas políticas sociais;

- Igualdade no acesso ao atendimento

Diretrizes:

- Descentralização político-administrativa dos programas, projetos, serviços e benefícios de atenção ao idoso;

- Participação da sociedade por meio de suas organizações representativas;

- Planejamento de ações a curto, médio e longo prazos, com metas exequíveis, objetivos claros, aferição de resultados e garantia de continuidade.

Mais do que na década precedente, é na primeira metade dos anos 2000 que se observa uma expressiva mobilização da sociedade civil brasileira a par de iniciativas governamentais em favor dos direitos sociais dos idosos. 
Uma breve análise das cartas, manifestos, e declarações (ver listagem bibliográfica) aponta a recorrência das preocupações e demandas relacionadas ao segmento populacional dos idosos. O quadro a seguir apresenta um resumo das deliberações de dois dos mais recentes eventos da área, no âmbito da sociedade civil.

\section{Encontro Nacional de Idosos - SESC - São Paulo - 2005 Carta dos Idosos à Nação Brasileira Avaliação da aplicação do Estatuto do Idoso}

- Desconhecimento do Estatuto pela maioria dos idosos

- Poder público ainda está longe de cumprir sua parte

- Saúde

- Críticas ao SUS e aos Planos de Saúde

- Necessidade de criação de unidades de referência por regiões

- Necessidade de acelerar implantação de Centros-Dia e Hospitais-Dia

- Programação da vacinação segundo ciclo climático de cada região

- Fornecimento gratuito de medicamentos, próteses, órteses e outros recursos

\section{- Educação, cultura esporte e lazer}

- Cultura: Situação é menos dramática do que em outras áreas

- Há respeito do direito ao ingresso com desconto

- Há mercado de turismo, espetáculos e outras atividades para idosos

- Mas, a maioria não tem acesso: parcos recursos de aposentadorias e pensões

- Há grupos de convivência, escolas abertas, universidades abertas

- Educação: o quadro é mais grave.

- Desconhecimento das condições sociais do envelhecimento

- Falta de programas específicos para os idosos

- Grande número de idosos analfabetos

- Falta de verbas e de equipamentos adequados

- UATIs são pagas e oferecem poucas vagas (maioria)

- Criação de cursos de formação e capacitação profissional

- Programas de inclusão digital

- Criação de cursos, universidades e escolas abertas públicas e gratuitas

- Valorização do idoso como transmissor de memória histórica, tradições e valores culturais

- Valorização da troca intergeracional de experiências.

- Abertura de horários e espaços especiais nos meios de comunicação

- Inclusão da educação para o envelhecimento nas grades curriculales 


\section{- Profissionalização e trabalho}

- Criação de serviços de informação, cadastramento e recolocação profissional

- Criação de programas de atualização, formação e qualificação profissional

- Incentivo fiscal para empresas que empregam idosos

\section{- Previdência Social}

- Garantia de manutenção do valor real dos benefícios iniciais

- Criação de forma de gestão transparente, quadripartite (governo, empresários, trabalhadores ativos e aposentados e pensionistas)

- Utilização do mesmo percentual atribuído ao salário mínimo para o reajuste das aposentadorias.

- Fim do desvio de recursos da Seguridade Social para o financiamento de outras atividades.

- Agilização do processo de concessão das aposentadorias: capacitação de pessoal para melhor atendimento e facilitação do cumprimento das exigências para o encaminhamento e aprovação dos processos.

\section{- Assistência Social}

- Manutenção e ampliação dos programas de proteção social existentes

- Aumento e qualificação da rede de entidades de longa permanência

- Alteração do limite de renda per capita de 1/4 para 1 salário mínimo para fins de concessão do BPC

- Extensão do BPC para idosos entre 60 e 64 anos em vulenrabilidade

- Não computação da aposentadoria ou pensão (1 SM) na composição da renda per capita familiar

\section{- Habitação}

- Cumprimento do Estatuto

- Modalidades de financiamento compatíveis com aposentadorias e pensões

- Programas habitacionais com real disponibilidade de vagas para idosos

- Acessibilidade por meio da eliminação de barreiras arquitetônicas

- Criação em larga escala e em todo o país de programas públicos alternativos, como a locação social, a bolsa-aluguel, repúblicas, condomínios e outras soluções cooperativas ou co-financiadas.

- Transporte

- Maior parte das empresas de transportes não cumprem dever de implementar melhoramentos ergonômicos e de segurança em suas frotas e locais de embarque e desembarque

- Capacitação e treinamento de condutores e outros funcionários

- Pressão contra a liminar do STJ que beneficiou empresas com a suspensão da reserva de vagas gratuitas e desconto no transporte interestadual. 


\section{- Fiscalização das entidades de atendimento}

- Fiscalização com objetivo de melhorar padrão de serviços

- Capacitação e instrumentalização dos Conselhos para função fiscalizadora

- Estímulo à criação de Conselhos Estaduais e Municipais

- Crimes contra a pessoa idosa

- Criação de delegacias e varas especiais de juizado de idosos

- Formação de equipes policiais especializadas

- Campanhas educativas quanto aos crimes contra os idosos

- Aplicação de penas alternativas de caráter educativo para agressores

- Criação de casas de passagem para proteção judicial

- Coibir propaganda enganosa de produtos financeiros para idosos e abusos como retenção de cartões magnéticos do INSS

\section{Manifesto do Movimento Social da Cidade de São Paulo Fórum do Cidadão Idoso da Cidade de São Paulo - 2006}

Apoio às propostas da Conferência Estadual de São Paulo e reiteração das seguintes prioridades:

- Revisão dos critérios da LOAS para facilitar a inclusão de idosos

- Reajuste condizente com os aumentos salariais

- Revisão da política de orçamento da saúde

- Criação de fundos através de recursos advindos do ICMS, IPI, loterias, fundos e outros

- Financiamento de propagandas educativas

- Equiparação da idade para os homens, segundo o critério para as mulheres, no que se refere a transporte

- Inclusão na Conferência Nacional dos temas aprovados na Conferência Metropolitana: moradia, transporte, trabalho e comunicação

- Presidente dos Conselhos de Idosos deve ser pessoa idosa

- Destinação de verbas em orçamentos públicos para que conselhos gerenciem suas ações com maior autonomia.

- Delegados eleitos sejam responsáveis pela implantação, gerenciamento e monitoramento da RENADI em seus estados e municípios.

Dentre os documentos mais recentes, destacam-se as propostas da Conferência Nacional dos Direitos da Pessoa Idosa, realizada em Brasília em 2006, em torno da criação da RENADI - Rede Nacional de Proteção ao Idoso, assim concebida: 
Organização da atuação pública (do Estado e da sociedade) através da implementação de um conjunto articulado, orgânico e descentralizado de instrumentos, mecanismos, órgãos e ações para realizar todos os direitos fundamentais da pessoa idosa do país.

A rede deverá ser integrada pelos seguintes interlocutores institucionais e serviços:

- Promotoria do Idoso

- Vara do Idoso

- Defensoria do Idoso

- Conselho de Direitos do Idoso

- Atendimento domiciliar ao idoso

- Residência temporária para idosos vítimas de violência

- Centro-dia para atendimento de idosos que necessitam de atendimento diário especializado e contínuo

- Oficina abrigada de trabalho para complementação de renda

- Casas-lares

- Capacitação de cuidadores de idosos e conselheiros

- Reserva de leitos em hospitais gerais

- Atendimento especializado nos consultórios de hospitais públicos por médicos geriatras.

Quanto à competência de coordenação da Política Social do Idoso a legislação estabelece que:

\section{No Município de São Paulo}

“Compete ao órgão municipal responsável pela assistência social coordenar a Política Municipal do Idoso e, especialmente:

I. Executar e avaliar a Política Municipal do Idoso; 
II. Promover as articulações entre órgãos municipais, e entre estes e entidades beneficentes e de assistência social, necessárias à implementação da Política Municipal do Idoso;

III. Elaborar proposta orçamentária no âmbito da promoção e da assistência sociais e submetê-la ao Conselho Municipal do Idoso".

\section{No Estado de São Paulo}

“Art. 10 - Compete ao Conselho Estadual do Idoso e aos Conselhos Municipais a supervisão e avaliação da Política Estadual do Idoso, no âmbito das respectivas instâncias político-administrativas".

\section{No País}

“Art. $5^{\circ}$ - Competirá ao órgão ministerial responsável pela assistência e promoção social a coordenação geral da Política Nacional do Idoso, com a participação dos conselhos nacional, estaduais, do DF e municipais do idoso.

Art. $7^{\circ}$ - Compete aos conselhos de que trata o artigo anterior a formulação, coordenação, supervisão e avaliação da política nacional do idoso, no âmbito das respectivas instâncias político-administrativas.

Art. $8^{\circ}$ - À União, por intermédio do ministério responsável pela assistência $e$ promoção social, compete:

I - Coordenar as ações relativas à Política Nacional do Idoso;

II - Participar na formulação, acompanhamento e avaliação da política nacional do idoso; 
III - Promover as articulações intraministeriais e interministeriais necessárias à implementação da política nacional do idoso;

IV- (vetado)

$V$ - Elaborar a proposta orçamentária no âmbito da promoção e assistência social e submetê-la ao Conselho Nacional do Idoso”.

Conforme a Res. $\mathrm{n}^{\circ} 109$ de 11/11/09 do CNAS - Conselho Nacional de Assistência Social, que estabelece a Tipificação Nacional de Serviços Socioassistenciais, estão previstos, dentre outros, os seguintes serviços para as pessoas idosas:

1. Serviço de Proteção Social Básica no Domicílio para Pessoas com Deficiência e Idosas, a ser executado por meio dos CRAS - Centros de Referência de Assistência Social;

2. Serviço de Proteção Social Especial para Pessoas com Deficiência, Idosos e suas Famílias, que prevê o atendimento no domicílio do usuário, centro-dia, Centro Especializado de Assistência Social (CREAS) ou Unidade Referenciada, incluindo o suporte aos cuidadores. Os usuários são pessoas com deficiência e idosos (as) com dependência, seus cuidadores e familiares. (Cf. anexo da Res. 109/09, p. 25).

Portanto, no âmbito do SUAS, segundo a nova tipificação acima referida, estão previstos serviços socioassistenciais básicos e especiais, que abrangem o atendimento no domicílio e que, no caso da proteção especial, incluem a assistência aos cuidadores, formais ou voluntários.

Na cidade de São Paulo, a Secretaria de Assistência e Desenvolvimento Social já desenvolve os seguintes serviços destinados ao segmento de idosos e que terão que ser readequados ou ampliados de modo a atender à tipificação: 


\begin{tabular}{|r|l|r|}
\hline \multicolumn{1}{|c|}{$\mathbf{N}^{\mathbf{0}}$} & \multicolumn{1}{|c|}{ SERVIÇOS } & \multicolumn{1}{|c|}{ VAGAS } \\
\hline 32 & Centros de Referência de Assistência Social (atendimento às famílias, & NSA \\
& incluindo-se as pessoas idosas) & 8000 \\
\hline 1 & Centro de Referência da Cidadania do Idoso & 7800 \\
\hline 105 & Núcleos de Convivência de Idosos & 184 \\
\hline 1 & Serviço de Apoio Sócio-Familiar (suplementação alimentar) a Idosos & 340 \\
\hline 3 & Centros de Acolhida especial para Idosos em Situação de Rua & 125 \\
\hline 3 & Instituições de Longa Permanência para Idosos & 165 \\
\hline 2 & Moradias para Idosos & \\
\hline
\end{tabular}

Fonte: PMSP/SMADS-2009

O aumento da longevidade combinado com a relativa queda da natalidade vem alterando o perfil demográfico brasileiro, com o crescente segmento de idosos a demandar serviços das diversas políticas públicas. Resta evidente que a oferta de uma ampla rede de serviços combinados com benefícios de transferência de renda, no âmbito das políticas públicas, terá que operar de modo articulado com as iniciativas do âmbito da sociedade civil (indivíduos, famílias, comunidades e organizações), com vistas à proteção social de pessoas idosas.

Vale considerar, entretanto, que as principais demandas dos idosos paulistanos extrapolam o âmbito de competência da Assistência Social, requerendo a ação integrada dos vários órgãos da municipalidade. O quadro abaixo apresenta, a propósito, a classificação das demandas registradas pelo Serviço Social do CRECI@ Centro de Referência de Cidadania do idoso no período de 10/10/05 a 20/01/06. 


\begin{tabular}{|l|c|c|}
\hline \multicolumn{3}{|c|}{ CENTRO DE REFERÊNCIA DE CIDADANIA DO IDOSO } \\
- SERVIÇO SOCIAL - \\
\hline \multicolumn{1}{|c|}{ DEMANDAS } & $N^{\mathbf{o}}$ & $\%$ \\
\hline Moradia e/ou abrigo & $\mathbf{2 5}$ & $\mathbf{2 2 , 3 2}$ \\
\hline Trabalho e renda & $\mathbf{1 6}$ & $\mathbf{1 4 , 2 8}$ \\
\hline Conflitos familiares & 15 & 13,39 \\
\hline - quanto àjugais, intergeracionais e outros & & \\
\hline Seguridade Social (previdência e assistência social) & & \\
\hline Saúde & 14 & 12,50 \\
\hline Transporte & 9 & 8,04 \\
\hline Violência, maus tratos, negligência e abandono & 9 & 8,04 \\
\hline Dívidas (energia elétrica, água, IPTU) & 8 & 7,14 \\
\hline Depressão e solidão & 4 & 3,57 \\
\hline Conflitos de vizinhança & 3 & 2,68 \\
\hline Outras demandas & 3 & 2,68 \\
\hline T O T A L & 6 & 5,36 \\
\hline
\end{tabular}

Fonte: Serviço Social do CRECI@ - SMADS - 2006

Portanto, à luz dos parâmetros internacionais, das deliberações dos principais eventos da área e, principalmente, da legislação social brasileira, a Política Social para as pessoas idosas terá que contemplar, dentre outros, os seguintes aspectos:

a. A alteração do perfil demográfico brasileiro com o crescente segmento de idosos, resultante da queda da taxa de natalidade combinada com a maior longevidade;

b. A presença feminina majoritária entre os idosos com o crescente protagonismo das mulheres na condição de provedoras a par do papel de cuidadoras, mesmo na velhice; 
c. O fato de que a atual rede de serviços está longe de assegurar o atendimento integral e preferencial ao idoso, nos termos da legislação social pertinente. Serão necessários investimentos de largo prazo para ampliar a oferta de modo a atender as demandas do crescente segmento de idosos;

d. As principais demandas: moradia, renda ou complementação de renda, seguridade social (saúde, previdência e assistência social), mediação e busca de equacionamento para conflitos familiares (conjugais, intergeracionais, em torno da partilha de bens, etc), serviços judiciários, demandas relacionadas à condição de consumidor de bens ou de serviços e prevenção contra a violência e maus tratos.

Sob essa perspectiva, será necessário avançar na implantação e consolidação do SUS - Sistema Único de Saúde, sob o princípio de que a saúde é "direito do cidadão e dever do Estado". Aqui estou referindo-me ao cidadão ou cidadã de todas as idades. O segmento de idosos, porém, apresenta demandas específicas em função de sua peculiar condição. Envelhecer não é adoecer. Mas, é evidente que as pessoas idosas são mais vulneráveis a certas patologias.

A experiência recente de implantação de CRIs - Centros de Referência do (a) Idoso (a) dispondo de serviços ambulatoriais de várias especialidades, combinados com atividades culturais e socioeducativas, tem se revelado positiva, sob a perspectiva do atendimento integral à saúde do idoso. Mas, será necessário buscar alternativas para atendimento domiciliar, observando-se o disposto no art. 230 da Constituição Federal, parágrafo $1^{\mathrm{o}}$, e no artigo 15 do Estatuto do Idoso.

Tendo em vista aqueles casos em que estejam esgotadas todas as alternativas para cuidados ao idoso (dependente ou semi-dependente) na própria família ou na 
comunidade, trata-se de reavaliar a modalidade de abrigamento institucional, rompendo-se, definitivamente, com a velha prática de confinamento dos idosos em "asilos". E terão que ser criadas diferentes modalidades de atendimento destacando-se, no caso do idoso dependente de cuidados para as atividades funcionais ou instrumentais da vida diária, as chamadas "instituições de longa permanência" para atendimento integral (psicológico, social, médico, odontológico, jurídico, etc). Impõe-se ainda a necessidade de organização de um sistema de formação continuada de cuidadores informais e de cuidadores profissionais para os serviços públicos e privados.

Quanto à Previdência Social, será necessário resistir às reformas que têm representado mais uma forma de expropriação e confisco aos trabalhadores, assalariados em geral, servidores públicos e idosos aposentados, obrigando-os a trabalhar mais, contribuir por mais tempo, aposentar-se mais velho, receber menos e continuar contribuindo na condição de inativos. Trata-se de pugnar pela previdência universal, solidária, sob gestão pública, contra as pressões pela redução da cobertura e pela privatização. A reforma defensável é aquela que favoreça a ampliação da filiação à Previdência Social, universalizando a cobertura social. Isso depende, evidentemente, de retomada do crescimento econômico e geração de empregos. Então, será necessário definir formas para a filiação da grande parcela da população economicamente ativa que se encontra fora do sistema previdenciário. Este é o caso, por exemplo, dos trabalhadores informais (sem carteira assinada e sem acesso aos direitos trabalhistas e sociais).

No âmbito da Assistência Social, será necessário ampliar a cobertura do BPC - Benefício de Prestação de Continuada (um salário mínimo) integrante da Política Nacional de Assistência Social, segundo preceito constitucional, para pessoas com mais de 65 anos e que não sejam cobertas pela Previdência Social. Para isso, terão que ser 
revistos os critérios de elegibilidade para o benefício, especialmente a exigência de renda per capita familiar de, no máximo, 1/4 do salário mínimo, altamente restritiva do acesso.

Será necessário regulamentar a concessão de benefícios eventuais mediante pronto atendimento e, no caso do segmento de pessoas idosas, na forma de suprimentos relacionados à proporção de conforto em face das limitações para as atividades funcionais ou instrumentais da vida diária. Nesse caso, sobressai a questão do fornecimento regular de medicamentos, órteses e próteses. E os benefícios eventuais (auxílio natalidade e funeral, conforme artigo 22 da LOAS) dependem ainda de regulamentação nas esferas federal, estadual e municipal para a sua concessão.

O suporte às famílias de idosos ou com idosos co-residentes, na forma de transferência de renda, deve combinar-se com a prestação de serviços socioeducativos. Nesse caso, trata-se de ampliar a cobertura do PAIF, por meio das ações dos CRAS Centros de Referência em Assistência Social.

A recente experiência de criar telecentros nos quais os idosos possam ter contato com os recursos da informática e acesso à Internet, precisa ser ampliada, sob a perspectiva da inclusão digital.

Na área de habitação, será necessário considerar alternativas à lógica do mercado. No elenco das necessidades sociais básicas, a habitação é a mercadoria mais cara e de difícil acesso. O mercado exclui pela baixa renda e pelo alto risco representado pela idade do interessado, dentre outras “exclusões". Vale considerar, a propósito, que a maioria dos benefícios previdenciários restringe-se a um salário mínimo. Portanto, o atendimento à demanda por moradia, no caso das pessoas idosas, não pode ser equacionado por meio dos procedimentos convencionais como: financiamento de longo 
prazo, restrições a pessoas idosas ou exigências para sua inscrição em programas com base em critérios securitários, entre outros.

Destacam-se, destarte, as alternativas do tipo "repúblicas" para idosos (independentes), subsidiadas pelo poder público, além de outras modalidades como a da locação social ou bolsa-aluguel, preconizadas na literatura da área e que parecem ter maior viabilidade se comparadas com as operações convencionais do mercado imobiliário As soluções do tipo "vila dos idosos" devem ser evitadas pelo que representam de risco de confinamento e segregação. Isso é diferente da reserva de cotas - um certo número de unidades - para idosos nos conjuntos habitacionais, o que, ao contrário das "vilas", favorece o convívio intergeracional e comunitário.

A ampla divulgação do Estatuto do Idoso, por meio de linguagem simples, clara e direta, na forma de cartilhas e folders, além da realização de campanhas e eventos regionais em torno das medidas para a implantação da RENADI podem ser instrumentos em favor da ampla mobilização da sociedade civil (docentes, pesquisadores, militantes da área, estudantes, profissionais, representantes de ONGs e, especialmente, fóruns representantivos dos próprios idosos e os conselhos nacional, estaduais e municipais de idosos, entre outros atores) para fazer cumprir a legislação.

Em suma, na contramão do contrarreformismo neoliberal que esvazia o papel social do Estado em favor do mercado e do capital, será necessário ampliar as políticas sociais em geral e aquelas voltadas para o segmento dos idosos, em particular, revertendo as atuais prioridades das políticas econômicas em torno da formação de superávit primário para o pagamento dos juros da dívida pública. 


\begin{abstract}
Among initiatives to denounce the "anti-elderly culture", marked by prejudice and segregation, this text consists of a critical approach of the main aspects of the Brazilian Social Policy for the Elderly People. It highlights legal texts as well as civil society manifestations, especially in the last twenty years, in favor of the social rights of the elderly. It adopts the Statute for the Elderly as the most important reference. Synoptic panels are used due to the didactic nature of the text, written with the purpose of giving subsidies for both technical and operative decisions in the field under discussion.
\end{abstract}

KEYWORDS: Elderly people, Old age, Ageing, Social Policy, Social Legislation

\title{
REFERÊNCIAS BIBLIOGRÁFICAS
}

BRASIL. Leis, Decretos, Resoluções, Portarias, Ordens de Serviço, Editais

Constituição Federal (Artigos 203, 226, 230), 1988

Constituição Estadual (Artigos 277 e 278 - III)

Lei Orgânica do Município (Artigos 225 a 227)

Lei n. 8.842 de 04/01/94 - Política Nacional do Idoso

Dec.1.948 de 03/7/96 - Regulamentação da Política Nacional do Idoso

Lei n. 9.892 de 10/12/97 - Política Estadual do Idoso

Lei n. 13.834 de 27/11/03 - Política Municipal do Idoso

Lei 8742 de 07/12/93 - Lei Orgânica da Assistência Social, 1993

Lei n. 10.741 de 01/10/03 - Estatuto do Idoso

Decreto n. 42227/02 - Cria o Conselho Nacional dos Direitos do Idoso - CNDI

Decreto n. 1.948/94 - Regulamenta a Lei n. 8.842/94 - Política Nacional do Idoso

Lei 10.012 de 13/12/85 - Assentos reservados no transporte coletivo.

Lei 11.109 de 31/10/91 - Setor especial para atendimento a idosos nos órgãos da administração municipal 
Lei Estadual 7.466 de 01/08/91 - Atendimento prioritário ao idoso.

Lei 11.248 de 01/10/92 - Atendimento preferencial em estabelecimentos comerciais e serviços

Lei 11.381 de 17/06/93 - Isenção da tarifa de ônibus - Mulheres com mais de 60 e homens com mais de 65 anos.

Lei 11.614 de 13/07/94 - Isenção do IPTU (imóvel do patrimônio de aposentados, pensionistas e beneficiários da RMV)

Lei 12.325 de 16/04/97 - Meia entrada para aposentados nos cinemas, teatros, espetáculos e eventos esportivos.

Lei 12.326 de 16/04/97 - Dia Municipal de Vacinação do Idoso (Dec.36.851 de $15 / 5 / 97)$

Lei 12368 de 13/06/97 - Adequação das unidades esportivas Lei 12365 de 13/6/97 - Atendimento preferencial em postos de saúde e hospitais Lei 12.604/98 - Política Municipal de Atenção à Terceira Idade Lei 12.633 de 06/05/98 - Programa Permanente de Treinamento e Reciclagem para motoristas, cobradores e fiscais de empresa de ônibus direcionado à pessoa idosa. Lei 12.940 de 07/12/99 - Programa Terceira Idade em Movimento Lei Estadual 10.779 de 09/03/01 - Cadeiras de rodas em shopping centers Lei 13.642 de 08/09/03 - Notificação dos casos de violência contra o idoso.

Dec. Estadual 23250 de 1/2/85 (?) - Atendimento preferencial em órgãos estaduais Dec. 3382/91 - Atendimento especial à população idosa Dec. 32975 de 28/01/93 - Regulamentação da Lei 11248 Decreto Municipal 36211 de 09/07/96 - Leite para a Vovó. Dec. 37030 de 27/08/97 - Regulamentação da Lei 12365

Dec. 4227/02 - Criação do Conselho Nacional dos Direitos do Idoso - CNDI Revista Serviço Social \& Saúde. UNICAMP Campinas, v. X, n. 11, Jul. 2011 
Dec. Federal n. 5130 de 07/07/04.

Portaria 2854/00 - Modalidades de Atendimento

Edital n. 012/2006/SMADS - Chamamento para a celebração de convênio para o desenvolvimento de incubadora social para o CRECI@, DOM de 21/03/06.

\section{CARTAS ABERTAS E MANIFESTOS}

Carta do Idoso do Município de São Paulo - Cidadania de Fato. São Paulo: Grande Conselho Municipal do Idoso, Corpo Municipal de Voluntários, Secretaria do Governo Municipal, Prefeitura do Município de São Paulo, 1991.

Carta Aberta à Nação. Bertioga: Assembleia Nacional de Idosos, SESC, 6 a 12 de abril de 1999.

Carta do Idoso do Município de São Paulo - Cidadania de Fato - São Paulo: Grande Conselho Municipal do Idoso, Secretaria Municipal do Governo, Coordenadoria da Participação Popular, Prefeitura de São Paulo. 2001. (revisão e atualização da Carta de 1991)

Política Municipal do Idoso. Reconstruindo a cidade para todas as idades. São Paulo: Pré-Conferência da Política Municipal do Idoso da Cidade de São Paulo, Anhembi Auditório Elis Regina, setembro de 2002.

Carta de Ouro Preto: Desigualdades Sociais e de Gênero e Saúde dos Idosos no Brasil. NESPE, FIOCRUZ, UFMG, 2002.

Carta do Idoso. Cidadão idoso unido e organizado. Ibiúna: Fórum do Cidadão Idoso da Cidade de São Paulo - Região Leste, 2004. (Toma como referência a Carta de 2001)

Carta dos Idosos à nação brasileira avaliando a aplicação do Estatuto do Idoso. Encontro Nacional de Idosos, SESC São Paulo, 04 a 07 de outubro de 2005. 
Representantes da área de Gerontologia querem a inclusão da matéria na nova tabela de áreas de conhecimento. Carta Aberta à Comissão Especial de Estudos. CNPq, CAPES e FINEP, UNICAMP, PUCSP, PUCRS, UCB, USP-Leste, outubro de 2005.

Manifesto do Movimento Social da Cidade de São Paulo. Fórum do cidadão idoso da cidade de São Paulo. Brasília, 2006.

Deliberações finais distribuídas por eixo temático da I Conferência Nacional dos Direitos da Pessoa Idosa. Brasília, 08 de junho de 2006.

\section{MANUAIS E CARTILHAS:}

Manual do Usuário Idoso. Conforto e Respeito ao Cidadão. São Paulo: Secretaria dos Transportes Metropolitanos, Cia Paulista de Trens Metropolitanos, EMTU, janeiro de 2006.

Conheça mais sobre o BPC - Um direito garantido pela Constituição Federal. Brasília: Ministério da Previdência Social e Ministério do Desenvolvimento Social e Combate à Fome.

BPC - Benefício de Prestação Continuada $-4^{\mathrm{a}}$ revisão. São Paulo: Secretaria de Assistência e Desenvolvimento Social, Prefeitura de São Paulo, 2005.

Idoso. Cidadania de fato. Ações intersecretariais. São Paulo: Prefeitura Municipal. Gestão 2001-2004.

Manual de Saúde do Idoso. SMS, Prefeitura de Santos.

\section{AUTORES}

BRUnO, M. et al. Política Municipal do Idoso. Texto base. São Paulo: Grupo de Trabalho Intersecretarial, Prefeitura de São Paulo, 24/06/2002. 
CAMARGO, J. M. Política Social no Brasil: prioridades erradas, incentivos perversos. Revista São Paulo em Perspectiva, vol. 18, n. 2, São Paulo, abril/junho/2004.

Como avaliar casas de repouso para idosos. Disponível em: www.portaldoenvelhecimento.net. Acessado em 23/11/05.

GOLDANI, A. M. Relações intergeracionais e reconstrução do Estado de Bem-Estar. Por que se deve repensar essa relação para o Brasil. In: CAMARANO, A. A. (Org). Os novos idosos brasileiros. Muito Além dos 60? Brasília: IPEA, 2004.

NERI, M. Crianças, nossos parias. In: Conjuntura Econômica, março de 2000, p. 44-7 Planejamento ignora idosos, diz especialista. São Paulo: Jornal Folha de São Paulo, p. C-3, 28/12/05.

RAMOS, V. Na rua, idoso é a principal vítima do trânsito. São Paulo: Jornal Folha de São Paulo, caderno Cotidiano, P. C-1, 28/12/03.

SAAD, P. M. Transferência de apoio intergeracional no Brasil e na América Latina. In: CAMARANO, A. A. (Org). Os novos idosos brasileiros. Muito Além dos 60? Brasília: IPEA, 2004.

\section{OUTROS}

Construindo e integrando a rede nacional de proteção e defesa da pessoa idosa. Brasília: I Conferência Nacional dos Direitos da Pessoa Idosa, Ministério do Desenvolvimento Social e Combate à Fome, Secretaria Nacional de Assistência Social, 23 a $26 / 05 / 06$.

Contribuições do MDS a I Conferência Nacional dos Direitos da Pessoa Idosa. Construindo a Rede Nacional de Proteção e Defesa da Pessoa Idosa. Brasília, 23 a 26 de maio de 2006. 
Deliberações finais distribuídas por eixo temático da I Conferência Nacional dos Direitos da Pessoa Idosa. Brasília, 08 de junho de 2006.

Padrões mínimos de financiamento de serviços e programas de atenção à pessoa idosa. Garantia de direitos e cumprimento de deveres para um envelhecimento saudável com qualidade de vida. Brasília: Ministério do Desenvolvimento Social e Combate à Fome, Secretaria Nacional de Assistência Social.

Contribuições do MDS a I Conferência Nacional dos Direitos da Pessoa Idosa Construindo a Rede Nacional de Proteção e Defesa da Pessoa Idosa. Caderno de Estudos, Desenvolvimento Social em Debate, Brasília: MDS, 2006. 